\title{
INTRODUCTION INTO HEALTH-RELATED FOLKLORE AND ITS RESEARCH: FROM FIRST-HAND EXPERIENCES TO SECOND-HAND NARRATING MODELS
}

\author{
Reet Hiiemäe \\ Senior Research Fellow \\ Department of Folkloristics \\ Estonian Literary Museum, Estonia \\ reet.hiiemae@folklore.ee
}

\begin{abstract}
By accentuating the central keywords and observations of the articles published in this special journal issue, the author - situating the articles in a broader theoretical framework - offers a glimpse at the role of the humanities in the research of the realm of health in such a unique period as the Covid-19 pandemic. The author concludes that based on the complexity of the topic (its physical and mental, individual and collective angles, impact of the mass media and partly recycled narrative models), health research needs to take into consideration the topic's social, narrative, religious, belief, and other aspects in a nuanced way, and here folkloristic and medical anthropological approach with its specialized methodology and empirical groundedness can offer significant added value.
\end{abstract}

Keywords: Covid-19, dialogues of disciplines, health beliefs, health folklore, vernacular medicine

\section{MULTIDIMENSIONALITY OF HEALTH}

Although "Health" was chosen as the general title of this special journal issue already before the Covid-19 crisis, the extraordinary timing of the editing work - in the middle of the pandemic - left its imprint on it and all articles are quite expectably at least in some sense related to the coronavirus, describing, for example, changes in the religiosity and the emergence of new forms of rituals during the crisis but also representations of alternative medicine in the media, new facets of the vaccine hesitancy problematics, characteristic features of health-related conspiracy theories and other narratives, and the rise of emblematic hero and horror figures during the same period. The geographi- 
cal grasp of the journal issue is remarkably wide - analyses of the situation come from Estonia, Finland, Bulgaria, Netherlands, Udmurtia, Tanzania, and even as a global cross-section. A couple of the articles - the ones from Thomas Ndaluka et al. and Angelina Ilieva - are elaborations of the papers that were presented in the thematic international autumn school "Dialogues with Health" for PhD students, which was held in November 2020 in Värska (Estonia). There is an overview of this autumn school in the news section of this journal (Ilieva actually raised her topic already in August 2020 at the conference "COVID-19-I: Coping strategies and communication models" from slightly different angles). One of the conclusions of the autumn school was that, more clearly than many earlier crises, Covid-19 has exemplified the multitude of combined dimensions that approaches to health can take. Besides purely medical and bodily outputs, significant social, religious, narrative, emotional, and material-technological aspects arise simultaneously, and need to be taken into consideration in research as well as in practical health care and policymaking.

The impact of emotions has especially been pointed out as a trigger for the development of alternative health explanation models and practices; for example, Nina Jankowicz (2020) notes in a generalizing way that disinformation runs on emotion. Yet so do also other types of information, including health information representations in the mainstream media. As the topic of health directly touches and concerns everyone, there is a huge potential for emotional reaction. It has also been observed that in the case of a clash of different worldviews, it is not sensible to fight with merely strong emotions against information that qualifies as health misinformation from the viewpoint of the official medical discourse. Of course, there are cases when sober and rational arguments have equally marginal effect. Until feelings of powerlessness or other reasons that feed a health belief do not fade, and the belief does not exhaust itself or become boring to its users, it may continue persisting, even more so when a belief or theory helps to work through an emotional burden. Thus, health beliefs can sometimes also have a function of constructive psychological self-help - as long as they do not obtain an extreme form and their users do not isolate themselves into a closed like-minded group.

There are many factors (e.g. the personality and reaction type of a person) that can contribute to the calming, constructive, or frightening impact of alternative health theories. Some booms of certain beliefs or approaches go through their natural life cycle and are eventually abandoned; however, in the case of the ones that persist tenaciously, it is worth investigating which aspirations they fill that they are continuously needed. In the context of vaccine problematics, Marko Uibu analyses some of such functions in this journal issue. 
At the same time, the handling of health-related emotions and insecurities depends very much on a particular narrative. It is clear that stories shape our perceptions of disease (cf. Lee 2014) and different stories can do it in a positive or negative way. It is often possible to avoid catching a disease, but it is almost impossible to avoid topical messages and narratives (media texts, experience stories from relatives and friends (and their friends), rumours, legends, conspiracies, memes), especially those related to more serious or more prevalent diseases. Most of all people thirst for getting an answer to the question of how to keep oneself safe - a majority of beliefs and narratives revolve around this very question. In all cultures, people's perceptions and belief systems regarding health are closely tied to the basic survival instinct and universal fundamental values, such as "those concerned with the maintenance of life and the loss of life and to certain conceptions of "the good life" (Alver 1995: 22). As Jon Lee notes, the differences that exist between the answers given by a doctor and a layperson thus emerge not because of the question that focuses on health and safety in both cases, but because of the different worldviews held by those groups as a result of their training and experience (Lee 2014: 2). Combined with particular health theories are usually understandings of the right and wrong behaviour, which can be based on very different information sources and sometimes limit themselves to passive prevention and avoidance, yet in other cases take the form of active intervention. All these dimensions deserve a scholarly analysis.

\section{FINETUNING OF RESEARCH APPROACHES}

Dorothea Lüddeckens and Monika Schrimpf (2018: 6) point out that health and healing are a contested research field; according to their observation, studying, for example, traditional and alternative medicines inevitably leads to accusations in partiality: one is blamed either for taking sides in favour of biomedicine or advocating alternative healing systems without sufficiently pointing to the possible drawbacks that these imply. This tendency also applies to the research of alternativity in a wider sense: alternative theories and those who show interest in them without expressing outright disgust (even if it is just scholarly interest from the viewpoint of cultural research, social psychology, and political science) often risk being viewed as pathologized (cf. a similar thought in Butter \& Knight 2018: 33) because dealing with such heavily connotated topics openly is not considered as serious research. Thus, it is important to be aware that researchers themselves would not end up silencing each other while using the same polarizing and demonizing scripts that we meet in vernacular debates. 
At the same time, folklorists, medical anthropologists, and representatives of other humanities can have a unique role in studying vernacular health concepts, narratives, and behaviour while having the necessary research tools that enable them to see wider patterns of vernacular reaction behind the clusters of narratives from individuals - narrative scripts, diachronic and synchronic changes in these scripts, universalities, key metaphors, mental maps and their creation mechanisms. Folkloristics, especially, critically scrutinises information of various levels and its sources, making different groups (including small ones) audible. Such a specialized methodology and empirical groundedness can offer significant added value to biomedical approaches or quantitatively based sociological surveys. The ideologies and values that rise from clearly mentioned scripts and contexts have an impact on health attitudes and behaviour. So, for example, some alternative views and critics related to the official medical system and its approaches (e.g., vaccination, restrictions) are much more sharply accentuated during the corona crisis than during other times. Yet at the same time it is deductively expectable that the emerging vernacular health theories have to resonate with the already existing worldviews in order to gain ground, or - as some researchers have shown - people first and foremost pay attention to what confirms the already existing experiences and beliefs, and lived experience of a close family member, and this information often outstrips the lived experience of the many, because the many show up as mere statistics (Bodner et al. 2021). Thus, it deserves more scholarly analysis and underlining in which cases there is a higher probability that narrative logic goes into conflict with the logic of statistical facts.

Several researchers have emphasized the need to pay more attention to which health-related views and in which contexts are given voice publicly. For example, Charles Briggs and Clara Mantini-Briggs (2016: 5-6) analyse how the uneven distribution of rights to produce and circulate knowledge about health is closely related to health inequities. Believing in some alternative health theories can be sometimes irrational and harmful but the conclusion that such theories are always per se dangerous cannot be taken for granted automatically. Thus, the actuality that some theories seem extreme and illogical does not mean that all others can also be deemed as incorrect or ridiculous. Here again, certain patterns of information production, established power relationships and information hierarchies play a role. For example, it can be observed with some regularity that the rhetoric of demonizing, polarizing, ridiculing, and doubting the adequacy of a representative of certain views only occurs if somebody's theories conflict with socially and politically recognized epistemic authorities - such as the mainstream media, scientists, medical professionals, government officials, historians, and other experts (cf. Räikkä \& Basham 
2019: 181). If similar arguments are presented by a journalist in a mainstream newspaper, the journalist's views are not any more called an alternative or conspiracy theory but investigative journalism.

Communication researchers and folklorists should also point more to the tendency that in public debates, believing in alternative health approaches or using these is mainly exemplified against the backdrop of the bizarrest theories (e.g. claims that the WHO cooperates with reptile aliens in creating certain health policies). One of the consequences of such an approach can be that a number of people start applying critical thinking to only those health theories that are not taken seriously by most people anyway, and are not alert to milder-sounding theories that do not fill such criteria of bizarreness. It is also relatively common that the public media and sometimes even researchers handle the users of certain health theories or healing practices as a monolith group. Joining such a group is described similarly to a fatal infection - once one affiliates, say, the group of MMS-users, there is no way back. Here more awareness of fluctuating group dynamics would be needed. While describing the thinking patterns of certain groups, similarly a more differentiated approach would be justified; for example, stereotypic accusations in credulity cannot be evenly applied to all alternative thinkers as many of them clearly make huge analytical efforts and weigh different information channels in order to make conclusions about the correctness of their views, thus working through much more information that the ones who only read selected mainstream newspapers or news portals but who are never pejoratively categorized of being irrational believers. Such a more nuanced approach would also help to find out in which cases the perception-psychologically grounded tendency occurs that even when comparing various information channels, some people still select only the information that supports their existing beliefs. In short, individuals are extremely diverse but in some cases the users of alternative health explanation patterns and curing, and mainstream thinking seem to have quite similar ways of communication and information processing: both are convinced that they own the correct information and believe that those who think differently are naive or biased.

Many scholars and journalists focus on the question about why people believe in alternative health theories and in conspiracy theories in general. Only few researchers (e.g. Räikkä \& Basham 2019) have dared to raise the opposite question - namely, why do people not believe in such theories. Räikkä and Basham argue that such a behaviour can be explained with conspiracy theory phobia which manifests when a person rejects conspiracy theories out of hand without any appropriate evaluation of the available evidence, or if their reaction towards such theories is explicitly one of mockery, contempt, or hostility. The 
risk of being stigmatised in relation to alternative thinking is so huge that it is much safer to believe dominant mainstream information. But automatically rejecting everything that differs from conventional information can cause people to give up healthy and justified critical thinking that could lead to informed conclusions and decisions.

Folklorists (and other humanitarians) can offer empirically grounded analyses of the combinations of alternative, evidence-based medical and rationalscientific health thinking in its complex forms and symbioses that can change in time and lead to mature informedness in some cases, but in others also to extremism. It is expectable, though, that the majority of people belong to the group with "coexisting worldviews and ontologies" (Utriainen 2016: 48) and derive their information from ever-increasing number of sources. Thus, the aim of folkloristics and neighbouring disciplines should not be stressing the dichotomy between the truth and non-truth or forbidding certain beliefs but rather exemplifying the emergence and spreading patterns of certain health beliefs and their causes, which can be related to economic and existential, past and present, individual and contextual insecurities in a combined way. All in all, the use of biomedical as well as alternative health approaches and their mixed forms arises from the need for self-protection and the desire for a fulfilling life.

\section{HEALTH IN MEDIA REALITIES}

As the article by Reet Hiiemäe and Terhi Utriainen in this volume and research from various Western countries confirm, the general attitude towards alternative healing and explanation theories and certain alternative approaches (e.g. vaccine hesitancy) in the mainstream media is ridiculing and stresses the dangerousness of such approaches. For example, vaccine hesitancy is often viewed as going hand in hand with the irresponsibility and credulity of the parents who are depicted as believing everything that they find on the internet (as if the internet would contain only non-plausible information). Yet, when interviewing such parents, it turns out that it is namely their feeling of responsibility towards the wellbeing of their children that trigger their alternative thinking and anti-vaccine behaviour - only their argumentation is not congruent with official viewpoints on the topic. Thus, publicly disparaging their behaviour or accusing them of acting irresponsibly cannot lead to positive results because they do not feel that such accusations are justified in their case.

Research has shown (e.g. Seale 2003) that when journalism aims to eradicate some risky health theories, their thorough description - even with pejorative epithets - is not an effective means but can produce the opposite effect. For 
example, through formats of science fiction, reality shows, and news journalism elements of alternative health theories reach millions of people who would probably otherwise not come into contact with them. Empirical media analysis shows that often reflections of alternative health theories in the mainstream media sound like copy-paste passages from alternative social media groups, just that a disparaging frame has been added. In this way they arouse interest in people who usually do not search information in alternative channels. Some authors (e.g. Schultz 2018) have compared the information presentation of conspiracy theories, folktales, and journalism and found significant similarities. Repeating the same content frames, narrative patterns, and even folktale archetypes in journalistic reporting perpetuates them on another level, sustaining for the media consumer the impression that these have an important message to spread. Even social media fact control marks sometimes rather increase than decrease in the curiosity of people as they arouse the feeling that the given information is something forbidden and secret. Additionally, fact controls are seldom perceived as neutral because even those cannot take place outside of certain ideologies.

In addition, an example about corona-deniers in Estonia (described in the article by Hiiemäe and Utriainen in this volume) shows that although the information about them was presented with strongly pejorative epithets, the number of people who joined their social media group increased rapidly after a TV show that confronted them. Thus, any type of visibility can attract new interest, and the interest of the already existing followers of a health approach will not fade simply after calling them stupid publicly. Alternative health theories and vaccine hesitancy that has reached new levels during the Covid-19 crisis are largely fed by the obscurity of information. Thus, a balanced fact presentation without sensationalising, demonising, and illustrating the information again and again with extreme cases would be more useful for increasing the clarity and transparency of information. Nevertheless, in the interest of covering the subject matter all-inclusively, it is fitting to add that public warning does not always appear without a moral reason: some promoters of alternative health approaches or products can indeed use outright lies, manipulate and play one group against the others, and gain profit from it, but without further analysing such cases neutrally and thinking about their motives critically it is difficult to understand which types of individuals use such methods and why. 


\section{PSYCHOLOGY, RELIGION, NARRATION, AND HEALTH}

When analysing health-related and other alternative theories, psychological moments rising from them are often pointed to, mainly stressing that they create fear, panic, and confusion, but the relevance of such material in psychological coping should not be underestimated either. There are still some - relatively few - authors who note that these approaches can also bring about subjective feelings of comfort, control, certainty, and solidarity (cf., e.g., Bodner et al. 2021). Psychological mechanisms of alternative health reasonings are important already in explaining the ways of information processing: various health theories and rumours offer critical avenues for discussing unfamiliar and dangerous situations, providing form, direction, and shape to these and release from stress in information vacuums and gaps (cf. Lee 2014: 173). Vernacular health explanations function as a way of giving understandable meaning to blurred matters in complicated times, offering emotional relief in at least some cases. It is therefore quite expectable that alternative theories gain more ground in the times of a pandemic or other disasters, when official health suggestions and restrictions sometimes change on a daily basis. For example, in a situation when a health crisis is accompanied with some other (e.g. political) crises, it is especially likely that some narrative shortcuts are sought to make sense of the state of affairs. When in January 2021 the sitting government was replaced with a new one due to a governmental crisis, and the new government changed the length of the compulsory quarantine from 14 days to 10 days without further explanation, many people were faced with the question of how the illness became suddenly less infectious just with the change of the government and respective new conspiracy theories emerged.

On the other hand, personal helplessness (e.g., fear because of the health of one's child) also seeks ventilation. If official information sites do not enable such a ventilation, it will find alternative outputs that can, in the worst case, take a radicalised form. Spontaneous social media groups are an important platform for sharing health-related experiences and opinions, but the reactions that the information shared in these groups can trigger can be different. As Marko Uibu notes in his article in the current volume, talking about health or particular health behaviours (vaccine-hesitancy) in social media groups does not necessarily lead to actual or persistent refusal of vaccines or other sciencebased medicines, or conflicts with representatives of the official medical system because group members already get their feelings of relief and empowerment from sharing respective stories. For example, Uibu's case analysis of personal experience narratives, which described contacts with the official medical system showed that - willingly or not - the descriptions of the situation are modified 
during re-narration, whereby the helplessness that was experienced in the real situation turns into controlling the situation in the narration. Here, the most important aspect of the discussion is not the call to rebel against the official medical system but getting confirmation from oneself and other group members that the narrator is a respectable person who is able to make right decisions.

Several articles in this special issue touch upon psychological mechanisms that are used for coping with the pandemic or other health crises; for example, processing of tensions through the prism of humour in memes, modified proverbs, and joking personal experience stories is elaborated in the article by Reet Hiiemäe, Mare Kalda, Mare Kõiva, and Piret Voolaid. Theo Meder takes another important angle, while comparing the thematical, narrative, and emotional niches that various genres (Covid-19 conspiracy theories, urban legends, memes) fill. He points out that in various genres, the expression of frustrations, malicious pleasures, fears, and feelings of distrust occurs in different ways. For example, the author initially expected that the jokes would contain plenty of morbid disaster humour, but it was not the case as the joke genre suited better for expressing other types of reaction. The contemporary legends and conspiracy theories, on the other hand, were polarizing and panicmongering, and their mistrust was mainly directed against the elite of politicians, scientists, doctors, and journalists.

The aspect of religion is continuously important in relation to health beliefs and practices. Already a decade ago, Pippa Norris and Ronald Inglehart concluded that while factors such as desire for human contact and solidarity or probing into the meaning and purpose of life continue to remain important, the importance of religion in the contemporary people's lives is increasingly reduced because of high levels of existential security in post-industrial societies (Norris \& Inglehart 2011: 245-246). However, global health risks like Covid-19 and other disasters show that physical as well as existential security can, even in the modern times, be not granted at all. It can even be said that because of the extremely fast information flows and the need to continuously process them, existential insecurity and stress related to the ambivalence of life is higher than ever before although the basic physical needs of the majority of Western people are met and, for example, diagnosing opportunities have never been so good as now. Therefore, turning to religion and forms of spirituality at least during crisis periods has not lost its importance and can be observed also in the sphere of health. Although biomedicine is at the highest level of technology, many unexpected and not easily understandable occurrences still take place (sudden illnesses or traumas, allergic reactions, etc.), triggering religious and belief-based interpretation. The mass media (including social media) enable many competing theories to spread fast and be simultaneously visible whereby 
the responsibility of making the right health choices lays with the individual. Due to such a multitude of avenues for information, the authoritative role of established power structures is challenged - besides official recommendations from the WHO and ministries of health, alternative theories and local group leaders and gurus are equally omnipresent, undermining the information distributed by these organs.

In the modern post-secular Western world, health-related vernacular approaches can reach from explanations and help models based on canonical religions to manoeuvres picked from vastly heterogenous forms of spiritualities. For example, for a number of esoteric circles 21 December 2021 was the day when the earth was supposed to shift into a new finer and cleaner energy, and for making this shift smoother and at the same time also decreasing the ravagement of Covid-19, a global mediation took place simultaneously everywhere at 21:21 on this day (partly related to the number combinations of 1 and 2). In this context, health is not viewed as a particular health condition of a single person, but the joint meditation can be seen as a way of averting the end of the world as a global irreversible health problem.

In this issue, Hiiemäe and Utriainen write also about media rhetoric that combines the topics of alternative medicine and religion in the mainstream Western journalism. The expression of novel religious outputs in finding empowerment in the times of a pandemic is the topic of the article by Thomas Ndaluka, Magolanga Shagembe, Jonas Kinanda, and Vendelin Simon. Their article describes the dynamics of religion in the times of Covid-19 in Tanzania, where the collected data showed an increase of the intensity level of religiosity during the pandemic. This activism was expressed in peoples' participation in religious activities like ecumenic religious gatherings, frequent prayers, and other religious practices, encouraged by the speeches of important public figures like the president of the state and church leaders who continuously positioned religion positively as a source of solace, hope, unity, and stability. It becomes clear from the article that the pandemic had a unifying role for different religions as they converged in the fight against one enemy - Covid-19. Thus, the authors show that the cooperation of religion and official medical structures is possible and in the case of a deeply religious nation and limited resources of the economic and medical system, spreading of official health advice with the help of religion can give good results.

Another interesting case study about the connection of health and religion comes from Nikolai Anisimov and Galina Glukhova, who concentrate on the Udmurtian context. The article highlights how, especially during major crises, it is difficult for people to give up their habitual rituals that strengthen the feelings of safety and solidarity, and followers of both Christianity and 
ethnic religion therefore find creative ways to continue organizing and attending them even in the changed conditions and despite the prohibition of mass gatherings. The article discusses the spring rites and summer prayers during the quarantine period, which partly found expression through new alternative ways of communication (e.g., outputs of rituals in social media; describing the pandemic situation through tradition-based humorous songs which helped to ventilate concerns related to the quarantine and self-isolation).

\section{RECYCLED REACTIONS TO MAJOR HEALTH CONCERNS}

A number of authors (Lee 2014: 4; Hiiemäe et al. 2021 in this issue) have pointed to remarkable similarities of epidemic narratives and reactions through history: when a Covid-19 narrative is compared to earlier narratives related to AIDS, H1N1, influenza, cholera or plague, the stories often bear parallel forms, plots, and meanings. I agree with Lee, who postulates: "Concerning novel diseases, people use certain sets of narratives to discuss the presence of illness, mediate their fears of it, come to terms with it, and otherwise incorporate its presence into their daily routines" (Lee 2014: 169). One of the repeated reaction models is stigmatization and polarization with the aim to mark the borders between good and evil, safe and dangerous. As the analysis by Hiiemäe and Utriainen (in this volume) about representations of alternative medicine in the mainstream media in the spring of 2020 indicates, media reaction also has certain recycled models, containing motifs of danger, risk, and stupidity and raising the need for sanctions related to healing methods used in contemporary spiritualities.

At the same time, recycled narration models also follow certain dynamics. For example, the article by Maris Kuperjanov, which gives a global picture of folkloric trends immediately after the beginning of the corona crisis in early spring 2020, makes clear that despite the fact that several narrative motifs are still recurring after a year, the foci of the topics were operatively changed according to the emergence of new information and findings about Covid-19 and these changes sometimes took place in the course of only a few days. For example, when in the beginning Covid-19 was depicted as something far and distant, only a couple of months later it was already viewed as a danger that is close and concerns the whole world either from a medical or economic viewpoint.

In crisis periods, personified heroes and scapegoats are needed in order to find a palpable channel for insecurities, aspirations, and other emotions. The article by Angelina Ilieva depicts the emergence of a positively presented emblematic figure in Bulgaria, offering a case study on the evolvement of the public image of the "Corona General" Ventsislav Mutafchiyski and the specific 
fan culture that emerged around his media persona during the first wave of the Covid-19 pandemic. The author describes how this one person who personified the hopes of very many people became extremely popular as a public figure as a fictional character, Mutafchiyski inspired numerous forms of vernacular creativity: poems, songs, material objects, jokes, fake news, conspiracy theories, and memes, becoming the focal point of a participatory pandemic.

On the other hand, as several authors have pointed out (e.g. Lee 2014: 74ff.), seeking a scapegoat tends to be used as a mechanism of projecting helplessness and anger that can bring along manifestations of cultural othering and xenophobia - for example, initially the danger of the corona pandemic was vernacularly heavily associated with the Chinese people, yet in some African countries it was, in turn, viewed as a white man's disease. Awareness of the researchers as well as health authorities of the patterns of othering is clearly necessary in the context of health crises.

\section{FUTURE VISIONS: DIALOGUES WITH PLURALISM AND AN ALL-INCLUSIVE RESEARCHER GAZE}

It is naturally possible to investigate the topic of health from many more angles than the limited volume of this special issue allows. For example, the group dynamics described in the article by Marko Uibu would certainly deserve a further analysis in the context of Covid-19 vaccines. A wide and important topic would be the changing of health approaches through one's life cycle and in the light of the increasingly longer life expectancy of the people in Western countries. Viewing health and artificial intelligence in cultural comparison and exploring other multidisciplinary combinations, for example with sociology, linguistics, and toponymy (see more about using place names in the context of pandemics in Hiiemäe 2020) would certainly give interesting results. The main focus of this special issue is on the context of the Covid-19 crisis that involves enormous numbers of people. But equally important are subjective opinions of individuals about their own health peculiarities and conditions and their empowering selfhelp narratives (e.g. about illness prevention, keeping a good immune system and mental health) that go hand in hand with wider therapeutic trends and discourses (cf. Salmenniemi et al. 2019).

Obviously, with the influence of globalizing health trends and perceptions, the pluralism and heterogeneousness of health beliefs and approaches is on increase and the interactions of media representations, personal and family traditions, teachings from exotic healing courses related to health and illness offer endless research horizons and aspects. For example, even the curriculum 
of an Estonian traditional ethnomedicine school offers subjects like tantra, Ayurveda, and Native American healing, but also courses on preventing illness through keeping mental and physical balance (see more on the topic in Kõiva 2020: 18). As it is possible to speak of multiple, fluctuating, and situative spiritual identities in Estonia (Hiiemäe 2021), the same applies to health-related belief worlds. There are more and more symbiotic relationships between various approaches that cannot be classified into fixed categories, therefore a dialogical and open researcher gaze seems appropriate. It is continuously topical to find ways for seeing a common ground in different health discourses, and reasonably mitigate the modes of hierarchic and polarizing information production. Methods of meaning-making and psychological coping are important in any period and will continue to be so also in the future, even during the eras of the most elaborated health technologies, and therefore their expressions are ongoingly worth studying.

\section{ACKNOWLEDGEMENTS}

Editing of this special issue and the writing of this introductory article were supported by the projects PUTJD962 (Estonian Research Council), TK 145 (Centre of Excellence in Estonian Studies through the European Regional Development Fund) and EKM 8-2/20/3.

\section{REFERENCES}

Alver, Bente Gullveig 1995. The Bearing of Folk Belief on Cure and Healing. Journal of Folklore Research, Vol. 32, No. 1, pp. 21-33. Available at https://www.jstor.org/ stable/3814395, last accessed on 11 March 2021.

Bodner, John \& Welch, Wendy \& Brodie, Ian \& Muldoon, Anna \& Leech, Donald \& Marshall, Ashley 2021. Covid-19 Conspiracy Theories: QAnon, 5G, the New World Order and Other Viral Ideas. Jefferson: McFarland \& Company.

Briggs, Charles L. \& Mantini-Briggs, Clara 2016. Tell Me Why My Children Died: Rabies, Indigenous Knowledge, and Communicative Justice. Durham: Duke University Press.

Butter, Michael \& Knight, Peter 2018. The History of Conspiracy Theory Research: A Review and Commentary. In: Joseph E. Uscinski (ed.) Conspiracy Theories and the People Who Believe Them. New York: Oxford University Press, pp. 33-46.

Hiiemäe, Reet 2020. Place Names and Epidemics: A Case Study of Handling Collective Fear. In: Chrismi Loth (ed.) Recognition, Regulation, Revitalisation-Place Names and Indigenous Languages. Proceedings of the 5th International Symposium of Place Names 2019. Sun Media Publishers, pp. 131-142. 
Hiiemäe, Reet 2021. A Hundred Forms of Spirituality in the Least Religious Country in the World. Journal of Religion in Europe, Vol. 13, No. 3-4, pp. 1-27.

Jankowicz, Nina 2020. How to Lose the Information War: Russia, Fake News, and the Future of Conflict. New York: I. B. Tauris.

Kõiva, Mare 2020. Pärimusmeditsiin ja globaliseeruvad tervisetrendid. [Etnomedicine and Globalising Health Trends.] Mäetagused, Vol. 75, pp. 5-24. https://doi. org/10.7592/MT2019.75.koiva.

Lee, Jon D. 2014. An Epidemic of Rumors: How Stories Shape Our Perceptions of Disease. Boulder: University Press of Colorado.

Lüddeckens, Dorothea \& Schrimpf, Monika 2018. Preface and Acknowledgements. In: Dorothea Lüddeckens \& Monika Schrimpf (eds.) Medicine-Religion-Spirituality: Global Perspectives on Traditional, Complementary, and Alternative Healing. Religious Studies 13. Bielefeld: Transcript Verlag, pp. 7-8.

Norris, Pippa \& Inglehart, Ronald 2011. Sacred and Secular: Religion and Politics Worldwide. Cambridge: Cambridge University Press.

Räikkä, Juha \& Basham, Lee 2019. Conspiracy Theory Phobia. In: Joseph E. Uscinski (ed.) Conspiracy Theories and the People Who Believe Them. New York: Oxford University Press, pp. 178-186.

Salmenniemi, Suvi \& Nurmi, Johanna \& Perheentupa, Inna \& Bergroth, Harley (eds.) 2019. Assembling Therapeutics. Cultures, Politics and Materiality. New York: Routledge.

Schultz, Tanjev 2018. The Rumor Mill. On the Relationship between Journalism and ConspiracyTheories.JournalismResearch,Vol.2,No.1,pp.21-27.Availableathttps:// journalistik.online/en/essay-en/the-rumor-mill/, last accessed on 11 March 2021.

Seale, Clive 2003. Health and Media: An Overview. Sociology of Health \& Illness, Vol. 25, No. 6, pp. 513-531. http://dx.doi.org/10.1111/1467-9566.t01-1-00356.

Utriainen, Terhi 2016. Ritually Framing Enchantment: Momentary Religion and Everyday Realities. Suomen Antropologi, Vol. 41, No. 4, pp. 46-61. Available at https:// journal.fi/suomenantropologi/article/view/63058, last accessed on 11 March 2021.

Reet Hiiemäe is Senior Research Fellow at the Department of Folkloristics at the Estonian Literary Museum, Estonia. She is currently doing her postdoctoral studies at the University of Turku (project PUTJD962). Her main research areas are folk belief and belief narratives, contemporary folklore, and coping mechanisms in folklore.

reet.hiiemae@folklore.ee 